\title{
Concepção dos enfermeiros na estratégia saúde da família referente a uma capacitação problematizadora em um município do estado Pernambuco
}

\author{
Conception of nurses in the family health strategy, regarding a capacity for \\ problematization in the municipality of state Pernambuco
}
Concepción de las enfermeras en la estrategia de salud familiar, con respecto a la capacidad de problematización en el municipio de estado Pernambuco

Ana Rosa Falcão Ferreira de Melo ${ }^{1}$, Carmina Silva dos Santos ${ }^{1}$, Tereza Rebeca de Melo e Lima ${ }^{1}$, Jerônimo Faustino do Rego Filho*.

\section{RESUMO}

Objetivo: Compreender a percepção dos enfermeiros sobre a utilização de uma proposta metodológica problematizadora em uma capacitação com enfermeiros. Métodos: Foi realizada uma pesquisa descritiva, exploratória e qualitativa, no município da mata sul de Pernambuco. Os dados foram coletados mediante grupo focal, por meio de entrevista semiestruturada, utilizou-se a análise de Bardin no tratamento dos dados, obteve o Certificado de Apresentação para Apreciação Ética no 32004614.30000.5569. Resultados: As quatro entrevistadas variam entre 9 a 21 anos de formadas, com um tempo de atuação de 8 a 10 anos. A utilização de uma metodologia problematizadora pode contribuir para atuar nos problemas identificados, as falas apontam uma descrição sobre a percepção frente à metodologia problematizadora, demostram dinamismo, valorizando o conhecimento prévio de cada um, é possível identificar as mudanças ocorridas nos profissionais. Conclusão: que os enfermeiros conseguem definir o uso da metodologia problematizadora e descrevem que a mesma estimula o pensamento em conjunto e colaborou na mudança de prática pessoal.

Palavras-chaves: Metodologia, Educação em saúde, Educação em Enfermagem.

\section{ABSTRACT}

Objective: Understand the nurses' perception on the use of a problem-methodological proposal in a training with nurses. Methods: It was made a descriptive, exploratory and qualitative study, in the municipality of mata south of Pernambuco. Was carried out by six nursing residents, the data were collected through a focal group, through a semi-structured interview, the Bardin analysis was used in the data treatment, the Certificate of Presentation for Ethical Appreciation no 32004614.30000.5569. Results: The four interviewed numbers vary between 9 to 21 years of graduation, with a length of experience of 8 to 10 years. The use of a problematizing methodology can contribute to act on the identified problems, the statements point to a description of the perception regarding the problematizing methodology, show dynamism, valuing the prior knowledge of each one, it is possible to identify the changes that occurred in the professionals. Conclusion: It was observed that nurses can set the use of investigative methodology and described that it stimulates thinking together and collaborated on changing personal practice.

Key words: Methodology, Health education, Nursing education.

${ }^{1}$ Faculdade Pernambucana de Saúde (FPS), Recife - PE.

2 Universidade de Pernambuco (UPE), Recife - PE. *E-mail: jeronimofausto@yahoo.com.br. 


\section{RESUMEN}

Objetivo: Comprender la percepción de las enfermeras sobre el uso de una propuesta metodológica problemática en una capacitación con enfermeras. Métodos: Fue realizada se realizó un estudio descriptivo, exploratorio y cualitativo, en el municipio de mata al sur de Pernambuco. Realizado por seis residentes de enfermería, se recopilaron los datos a través de un grupo focal, a través de una entrevista semiestructurada, se utilizó el análisis de Bardin en el tratamiento de datos, el Certificado de Presentación para Ética Apreciación no 32004614.30000.5569. Resultados: Los cuatro entrevistados varían entre 9 y 21 años de graduación, con una experiencia de 8 a 10 años. El uso de una metodología problematizadora puede contribuir a actuar sobre los problemas identificados, los enunciados apuntan a una descripción de la percepción respecto a la metodología problematizadora, demuestran dinamismo, valorando el conocimiento previo de cada uno, es posible identificar los cambios que ocurrieron en los profesionales. Conclusión: se observó que las enfermeras pueden establecer el uso de la metodología de investigación y describió que estimula el pensamiento conjunto y colabora en el cambio de la práctica personal.

Palabras clave: Metodología, Educación para la salud, Educación en Enfermería.

\section{INTRODUÇÃO}

Os enfermeiros da Estratégia Saúde da Família desenvolvem seu processo de trabalho juntamente com demais membros da equipe, além de atividades que são comuns a todos. Esse profissional realiza ações específicas dentre as quais: supervisionar e ampliar o trabalho dos Agentes Comunitários de Saúde (ACS) e Técnicos em Enfermagem; assistir às pessoas (individual e coletivamente) que necessitam de assistência de enfermagem, acompanhando, ampliando a atenção e o cuidado às famílias (SILVA VG, et al., 2010). Porém para o enfermeiro conhecer a família é necessário conhecer seu funcionamento, os fatores que influenciam na saúde e na doença, bem como suas experiências. Entender a Saúde da Família como estratégia de mudança significa repensar práticas, valores e conhecimentos de todos os grupos envolvidos no processo de produção social da saúde, respeitando suas culturas (WEIRICH CF, et al., 2004).

A Educação Permanente em Saúde (EPS) adota como pressuposto pedagógico a noção de aprendizagem significativa - aprendizado de algo que faça sentido para os sujeitos envolvidos a partir da problematização dos processos de trabalho. Dessa forma, a educação permanente é entendida como aprendizagem no trabalho, quando o aprender se incorpora ao cotidiano das organizações e ao trabalho (ARRUDA MP, 2008).

Segundo a Resolução CNE/CES $\mathrm{n}^{\circ} 3$, de 7 de novembro de 2011, a qual instituiu as Diretrizes Curriculares Nacionais do Curso de Graduação em Enfermagem a formação do enfermeiro objetiva dotar o profissional de competências e habilidades, dentre elas, a educação permanente com destaque a introdução de métodos educacionais inovador como a utilização da metodologia da problematização, há quase 20 anos vem sendo utilizada no Brasil, principalmente nos cursos de graduação em enfermagem, porém há uma com forte resistência a estas inovações; a metodologia problematizadora considera que o sujeito pode transformar sua realidade a partir de sua inserção na mesma, é um processo de aprendizagem estimulados pelas instituições de ensino e pela literatura (COFEN, 2001; RIBEIRÃO PRETO, 2015; SES, 2014).

A secretaria de saúde realiza todos os anos, capacitações para profissionais de saúde que atendem aos trabalhadores do campo, inseridos na Zona da Mata, Sertão, Agreste e Região Metropolitana do estado (COMPANHIA EDITORA DE PERNAMBUCO, 2014). O Programa utiliza em suas capacitações a metodologia da problematização, a qual o aluno é levado à observação da realidade, identificação das possíveis causas do problema para então realizar um estudo mais critico e abrangente que é a teorização, para assim levantar hipóteses de soluções e aplicar à realidade, modificando-a. (SES, 2014) O processo educativo problematizador permite que os conteúdos trabalhados surjam da realidade, contribui para a percepção de um problema e consequentemente possibilita a transformação desta realidade (RIBEIRÃO PRETO, 2015). 
A partir das considerações, emergiu o seguinte problema de pesquisa, será que os enfermeiros da estratégia da família têm o conhecimento sobre uma capacitação problematizadora no estado. Para complementar a hipótese do estudo será traçado o seguinte objetivo compreender o Conhecimento dos enfermeiros na estratégia saúde da família referente uma capacitação problematizadora em município do estado.

\section{MÉTODOS}

O estudo caracteriza-se como sendo do tipo: descritivo, exploratório, com abordagem qualitativa. A composição da equipe interdisciplinar contou com: pesquisadora que conduziu o grupo focal, duas auxiliares doutoras: uma Enfermeira Doutora docente do curso do mestrado e a outra Médica Mestre docente do curso de mestrado de uma Faculdade de Pernambuco. Um observador doutor em Ciências da Saúde Faculdade de Medicina. O estudo foi realizado durante os meses de abril a maio de 2015, de um município situado do estado de Pernambuco. O município possui 60.091 habitantes, 18 Estratégia de Saúde da Família (ESF), sendo cinco localizadas na zona rural após aprovação do Comitê de Ética e Pesquisa (CEP), Certificado de Aprovação e Apreciação Ética (CAAE): 32004614.30000.5569. A amostra foi por saturação, este tipo de amostra consiste em uma interrupção de admissão de novos entrevistados para realização da pesquisa a partir da percepção por parte do pesquisador e de um balizador (pesquisador especializado neste tipo de abordagem) que está ocorrendo uma repetição ou redundância nas respostas emitidas (BRASIL, 2014).

No estudo, a amostra foi composta quatro por enfermeiros da ESF, que participaram no último ano de uma metodologia de ensino problematizadora, oferecida pelo Programa Chapéu de Palha - Saúde e que estavam atuando na Estratégia de Saúde da Família. Os participantes foram devidamente esclarecidos quanto aos objetivos da pesquisa e entrevistados mediante a leitura e assinatura do Termo de Consentimento Livre e Esclarecido (TCLE). Sendo Ihes garantido, a voluntariedade e o direito à desistência em participar do estudo, além do total anonimato e sigilo das informações confidenciadas.

As informações foram coletadas por meio de uma entrevista semiestruturada, em um auditório do referido município, com duração de duas horas e trinta minutos cada, os diálogos foram gravadas por meio digital, para posterior transcrição e análise das falas, através do software, ATLAS.ti Scientific Software Development $\mathrm{GmbH}$, Berlin, Germany. Foi utilizado como roteiro um instrumento elaborado pelos pesquisadores, contendo três perguntas norteadoras as quais remetem os entrevistados a expressarem seu entendimento com relação a uma metodologia problematizadora, como estar sua prática de trabalho após a capacitação recebida e identificar seus pontos fortes e fracos. As respostas foram gravadas, transcritas e avaliadas na íntegra após a coleta, seguida da análise das respostas. A fim de analisar as entrevistas, utilizou-se da técnica da análise de conteúdo (BARDIN L, 2014). Adotou-se uma codificação das representações, através da categorização, interpretação e o desenvolvimento de explicações e representações dos participantes, com vista ao alcance dos objetivos propostos na pesquisa (BARDIN L, 2014).

\section{RESULTADOS E DISCUSSÃO}

Perfez um total de quatro entrevistadas, variam entre 9 a 21 anos de formadas, com um tempo de atuação de 8 a 10 anos na ESF, todos com pós-graduação em sua área de atuação. A partir da análise dos resultados foram elaboradas as seguintes categorias: a) Problematização de cenários reais; b) Metodologias transformadoras do conhecimento; c) Aprendizagem colaborativa; d) Ações para prática: lidando com recursos disponíveis, nesta última foi necessário destacar a subcategoria: Autocuidado da equipe, por ser um ganho secundário da capacitação.

\section{a) Problematização de cenários reais}

A discussão do uso de metodologias ativas não é algo recente, é um tema que vem sendo discutido com êxito no âmbito da educação e estimulado seu uso. Paulo Freire faz menção ao tema quando afirma que a 
metodologia quando utilizada para o público adulto possibilita construir novos pensamentos a partir de experiências prévias e resolver problemas (PRADO ML, 2012). A proposta da utilização de uma metodologia problematizadora pode contribuir para atuar nos problemas identificados no ambiente de trabalho como pode ser observado na fala da participante abaixo.

\section{"... A gente vai atuar em cima do problema vendo (...) executando as atividades em cima do problema já existente." (Entrevistado 1).}

Atuar no problema é o princípio deste tipo de metodologia, o que se pode compreender que a entrevistada conseguiu não apenas relatar que resolve o problema identificado, mas que acima de tudo é capaz de identifica-lo e buscar soluções para o mesmo, tal atitude cumpre as etapas propostas pelo arco de Maguerez esplanadas em um estudo sobre um relato de experiência onde foi descrito as vivências de uma metodologia ativa, tais etapas são: Observando a realidade; identificando os pontos chaves; teorizando; identificando hipóteses de solução e aplicação na realidade. Ou seja, a fala da entrevistada remete a aproximação existente entre a percepção da profissional e o arco, onde permite empreender que a mesma passou por tais etapas, ou que mesmo que não tenha resolvido verdadeiramente o problema por ela elencado, mas consegue descrever o que compreende sobre este tipo de metodologia (ARAÚJO RCG, 2014).

Outra entrevistada corrobora com a percepção de que é importante conhecer os atores envolvidos no problema para buscar mudanças, envolvendo as observações elencadas quando diz:

“... Conhece a questão cultural, conhece a questão do conhecimento da própria comunidade e traz isso pra nossa realidade." (Entrevistado 2).

É possível identificar que a mesma busca observar o contexto em que a comunidade está inserida para construir soluções a partir da identificação previamente realizada, neste sentido permite-se como profissional observar a realidade do seu público alvo, fazer diagnósticos amplos sobre os determinantes que o cercam como a mesma faz menção a "questão cultural" e a "questão do conhecimento" para a partir de então buscar soluções para os problemas enfrentados considerando a realidade vivenciada na comunidade para que haja uma intervenção nesta realidade.

\section{b) Metodologias transformadoras do conhecimento}

A metodologia tradicional diverge de uma metodologia ativa, com um ponto chave, o pensamento. No entanto na metodologia de ensino tradicional, o professor é o centro do saber, onde o mesmo ao falar silencia os estudantes, estes se tornam sujeitos passivos no processo de aprendizagem. (CAVALCANTI RA, 1999).

Na metodologia ativa o estudante não é só permitido refletir sobre um tema discutido, mas também concordar ou discordar, por esta óptica o discente é possibilitado então de despertar seus pensamentos relacionados ao problema vivenciado. Estudo afirma que estudantes retêm apenas $10 \%$ do que ouvem após 72 horas, no entanto àqueles que ouvem, veem e fazem, são capazes de lembrar $85 \%$ após o mesmo período (DIAS P, 2001). As falas apontam uma descrição sobre a percepção frente à metodologia problematizadora:

“... É uma metodologia muito boa, porque ajuda a gente a pensar né? A gente vai procurando desenvolver... aquele tema e chegar a uma conclusão final eu acho maravilhoso (...) porque assim é muito mais prática e ajuda você a tá raciocinando" (Entrevistado 3).

"... Problematização é isso: problematizar os problemas que a gente vive no dia-adia e tentar trazer junto com a comunidade uma solução, que é chamado mudança de comportamento." (Entrevistado 2).

Observa-se que a primeira fala relata a percepção que a mesma tem após conseguir desenvolver o problema, ela enxerga que a metodologia é fácil de ser vivenciada, pelo fato de possibilitar o pensamento 
do indivíduo envolvido no processo da problematização, pois está relacionado com a sua realidade. Agregando também o conhecimento da comunidade para haver uma modificação na realidade. Isto consiste em uma forma de pensar diferente, pois é o que a metodologia provoca no indivíduo, a busca não sozinha e silenciada de uma solução, mas uma busca em conjunto, provocando o que a entrevistada define como "Mudança de comportamento".

\section{c) Aprendizagem colaborativa}

A aprendizagem colaborativa consiste em processos e estratégias que integram uma abordagem educacional na qual os alunos são encorajados a trabalhar em conjunto no desenvolvimento e construção do conhecimento. Também chamada de aprendizagem em grupo, está baseada no modelo centrado no aluno, promovendo a sua participação dinâmica nas atividades e na definição dos objetivos comuns do grupo (COMPANHIA EDITORA DE PERNAMBUCO, 2014). As falas a seguir demostram esse dinamismo de forma integrada, valorizando o conhecimento prévio de cada um.

"... Porque assim é muito mais prática e ajuda você a tá raciocinando, é como se você já soubesse, mas fosse só acrescentando e juntando, vai juntando as ideias de um com outro, quando vê o conteúdo final é ótimo." (Entrevistado 3).

"... Problematização é isso: problematizar os problemas que a gente vive no dia-adia e tentar trazer junto com a comunidade uma solução (...)"(Entrevistado 2).

É descrita nas falas, a compreensão que as entrevistadas têm frente da metodologia, pois descrevem que não estão sozinhas nas etapas em busca da solução dos problemas e podem discutir os mesmos e encontrar com êxito uma solução final envolvendo todos os atores do problema. Isso nos remete ao que afirma o estudo, que a tríade saber - aprendizagem - cognição, são construções sociais, expressas em ações de pessoas que interagem no seio de comunidades (JONASSEN DH e LAND SM, 2009).

\section{d) Ações para prática: lidando com recursos disponíveis}

A educação permanente busca não só atualizar o profissional, mas está relacionada à mudança de atitude, onde o indivíduo busca constantemente aprender e assim haver uma mudança da prática de forma competente, consciente e responsável (MINISTÉRIO DA SAÚDE, 2014). Mudar de comportamento não é algo fácil, é uma atitude que exige não apenas conhecimento teórico, mas, sobretudo uma maneira de pensar diferente, para que haja de fato implementação de atitudes diferentes, práticas diferentes.

A educação permanente tem como objetivo principal transformar práticas técnicas e sociais, utilizando uma pedagogia centrada na resolução de problemas (MITRE MS, et al, 2008; BERBEL NAN, 2011).Tendo como resultado a mudança, quer seja do ambiente, quer seja do profissional. A qual tem interesse de trazer aos profissionais, capacitações relacionadas ao trabalho vivenciado, e por essa razão é natural pensar/almejar que o profissional oriundo de uma capacitação, ele tenha desejo em modificar suas ações. No entanto, o fato do profissional participar de uma capacitação profissional não garante que o mesmo será realizado no ambiente de trabalho (SILVA IJ et al, 2009). As situações de dificuldade ou problema nos locais de trabalho, geralmente, são atribuídas às pessoas, por meio de treinamentos, "adequá-las", "reformá-las" ou enquadrá-las em novas lógicas. Tais treinamentos, entretanto, quase nunca alteram os processos de trabalho, não revisitam/enfrentam as desigualdades de acesso na vida, às condições precárias de trabalho, os processos de decisão e as relações de poder presente no trabalho (PASCHOAL AS, et al., 2006).

"... Então a gente se estimulou, só que ai tem outras coisas, que tem que ir atrás ai acaba a gente se acomodando e realmente, infelizmente a gente não foi adiante." (Entrevistado 1).

"... Que eu sinto dificuldade é pra atuar mesmo, por que assim, teve várias propostas lá no chapéu de palha que a gente sugeriu, mas a gente não consegue desenvolver por que é muita coisa pra trabalhar dentro do PSF e a gente não tem recursos suficientes pra isso." (Entrevistado 3). 
Percebe-se que as condições precárias relacionadas a não modificação da prática é a ausência de recursos necessários para implementar ações que foram elencadas no treinamento e é possível avaliar que todas as dificuldades que são encontradas no processo de trabalho, ou seja, na rotina da atividade laboral, faz com que o profissional fique desestimulado e haja uma acomodação para ele não seguir adiante com as propostas.

A partir das falas pode ser percebido que de fato não houve mudanças de prática na ESF, após a capacitação e ainda é possível observar na fala da Luíza, as propostas de mudanças foram feitas por eles mesmos (membros da equipe) a partir do conhecimento da realidade da comunidade e compreendendo os fatores que envolvem o contexto real e mesmo assim essas ações não foram desenvolvidas.

A metodologia problematizadora, é um modelo inovador onde há uma integração do ensino com relação entre teoria e prática, permitindo que o profissional/estudante seja capaz de atuar na realidade, buscando transformá-la, unindo a educação, com o trabalho e a comunidade, através de um censo crítico e reflexivo (MANCIA JR, 2004). A mesma foi elencada na pesquisa como um dos pontos fortes do Programa Chapéu de Palha, pois aproxima o estudante da realidade, estimulando-o à constante estudo, a tornando-o um sujeito crítico/reflexivo, tornando-se assim independente e motivado a aprender (MINISTÉRIO DA SAÚDE, 2005).

"... Metodologia muito boa, então assim a do ano passado não deixou nada a desejar eu gostei muito(...) lógico que tem a parte teórica, que tem que ter a parte teórica, mas era sempre vivenciando a questão da problematização, e mesmo na teoria eles sempre relacionam, associam com a realidade." (Entrevistado 1).

"É a mudança mesmo do cotidiano, da metodologia que é acessível pra todo mundo, (...) são atividades que a gente faz que a gente pode levar realmente pra unidade (...)por que as vezes a gente trabalha determinados cursos eles falam, mas é muito distante da realidade da gente e o chapéu de palha, não, ele realmente aproxima. " (Entrevistado 4).

Quando a entrevistada Júlia relata que “... determinados cursos eles falam, mas é muito distante da realidade da gente" ela refere-se a cursos de capacitação que são comuns acontecerem no âmbito da saúde, no entanto não levam em consideração o conhecimento que o discente vivencia na prática. A metodologia vivenciada pelo Programa Chapéu de Palha foi considerada um ponto positivo da capacitação, pois estimula o profissional a desenvolver as ações dentro do seu cotidiano de trabalho, trazendo pra sala de aula não meros conteúdos, mas problemas reais, enfrentados pela equipe de saúde que trabalha dentro da comunidade.

\section{“... Pontos fortes é o trabalho de problematização de conscientização de fazer o profissional analisar, repensar sobre sua prática." (Entrevistado 2).}

O processo da problematização força o indivíduo em meio a este tipo de metodologia, a pensar, a criar possibilidades para que sejam solucionados os problemas (SCHAURICH D, 2007). Foi interpelado as profissionais entrevistadas também sobre os pontos fracos da capacitação. No entanto as respostas não foram relacionadas à capacitação propriamente dita, mas as dificuldades enfrentadas pelos mesmos ao desejarem por em prática as atividades elencadas durante o processo de aprendizagem.

“... Você vê que você precisa de outras pessoas que não estão tão interessadas em te dar todo esse suporte que você precisa, e aí assim, você depender só de sua equipe, não tem como desenvolver isso só dentro da minha equipe, porque eu tô vendo que as atividades normais, assim, básicas de PSF tá difícil desenvolver... imagina a gente implementar alguma outra coisa ." (Entrevistado 3).

"não depende só da gente, a gente não tem o apoio da instituição,(...) do gestor (...) acho que teria que capacitar os gestores (...) a gente vem cheios de ideias, cheios de vontade, deveriam ter essas capacitações para outras instâncias e infelizmente não depende da gente..." (Entrevistado 1). 
A entrevistada Marta, cita a importância da capacitação dos profissionais, mas também dos atores envolvidos indiretamente no problema, os gestores. Dentro desta categoria é importante destacar uma subcategoria encontrada na pesquisa: Autocuidado da equipe. Pois a capacitação visa à transposição e troca de conhecimento para que o mesmo seja aplicado na realidade junto à comunidade, e através da pesquisa pode-se perceber um ganho secundário oferecido pela capacitação, visto que foi identificado que os profissionais não se viram meramente como agentes de mudança dentro da comunidade, mas também que poderia aplicar o conhecimento adquiridos em si mesmos.

A capacitação realizada pelo Programa Chapéu de Palha no ano de 2014 através da Secretaria Estadual de saúde teve como tema: Saúde do trabalhador, que transmitiu para os profissionais de saúde a importância do cuidado não só com os clientes/pacientes, mas também alertar para a importância do cuidado para quem cuida. A autora da Teoria do autocuidado Dorothea Elizabeth Orem, já mencionava e refletia a cerca do autocuidado, porém apesar de a Enfermagem ser uma ciência, onde se tem formação para o cuidar, os enfermeiros têm dificuldades em praticar o cuidado de si (MARIN MJS, 2010). E esta capacitação teve repercussão positiva para os profissionais que ali estavam, levando-os a compreender que não cabe a eles unicamente a se adaptar ao ambiente, mas sim interagir com o mesmo podendo ser transformado e transformar o ambiente, pois mudaram seus hábitos, portanto, modificaram sua realidade, que é o foco da metodologia problematizadora e o resultado final do arco de Margarez (MARIN MJS, 2010).

É possível identificar as mudanças ocorridas nos profissionais através das falas a seguir:

"... As principais mudanças, eu tô fazendo acompanhamento com a nutricionista (...) eu estava com obesidade grau I, agora estou com sobrepeso, quer dizer que já diminui (...)Tô fazendo acompanhamento com a nutricionista e tô fazendo atividade física(...)."(Entrevistado 4).

"... eu tô, no chamado plano alimentar, estou na reeducação mesmo, não é simplesmente perda de peso com medicação não, é uma coisa pro resto da vida, e foi uma coisa que eu aprendi no curso, a gente tem que mudar os hábitos, pra ter uma boa qualidade de vida e eu tenho que ter uma boa qualidade de vida pra poder passar isso para os nossos clientes..." (Entrevistado 2).

É possível observar ainda na fala da entrevistada que ela, além de estar convencida de que é algo que foi incorporado em seu cotidiano, à mesma ainda faz alusão sobre a sua preocupação em se manter saudável para despertar os usuários que por ela são assistidos.

\section{CONCLUSÃO}

Parte das entrevistadas relatou que após a capacitação perceberam mudanças na rotina de trabalho. Uma vez que os profissionais mudaram sua realidade pessoal, onde tal mudança é a essência da metodologia problematizadora e evidencia o autocuidado do profissional adquirido a partir da capacitação. É percebido que algumas dificuldades identificadas não estão relacionadas à metodologia propriamente dita e aplicada, mas sim às dificuldades que eles enfrentam em lidarem com os recursos disponíveis para aplicarem os conhecimentos adquiridos, como: acomodação, excesso de trabalho e envolvimento de outros atores.

\section{REFERÊNCIAS}

1. ARRUDA MP, et al. Educação permanente: uma estratégia metodológica para os professores da saúde. Rer. Brasileira de educação médica 2008; 32(4): 518-524.

2. BARDIN L. Análise de conteúdo. ed. Edições 70, 2014; 288p.

3. BERBEL NAN. As metodologias ativas e a promoção da autonomia de estudantes. Semina: Ciências Sociais e Humanas. 2011; 32(1): 25-40.

4. BRASIL. Ministério da Saúde. 2013. In: Resolução no 466, de 12 de dezembro de 2012. Diretrizes e normas regulamentadoras de pesquisas envolvendo seres humanos. Diário Oficial [da] República Federativa do Brasil. 
5. CAVALCANTI RA. Andragogia: a aprendizagem nos adultos. Rev. de Cl. Cirúrgica da PB, 1999; 6(4).

6. COMPANHIA EDITORA DE PERNAMBUCO. 2014. Programa chapéu de palha divulga ações em Cuba. Disponível em: http://www.cepe.com.br. Acesso em: 17 fev. 2019.

7. CONSELHO FEDERAL DE ENFERMAGEM (COFEN). 2001. Resolução CNE-CES no 3, Diretrizes Curriculares Nacionais do Curso de Graduação em Enfermagem. Rio de Janeiro.

8. DIAS P. Comunidades de conhecimento e aprendizagem colaborativa. In: Seminário Redes de Aprendizagem, redes de conhecimento, 2001; Lisboa. Portugal 2001. Conselho Nacional de Educação; 2011.

9. JONASSEN DH, LAND SM. Theoretical foundations of learning environments. New York: First Published, 200; 58$59 \mathrm{p}$.

10. MANCIA JR, et al. Educação permanente no contexto da enfermagem e na saúde. Rev Bras Enferm, 2004; 57(5): 605-610.

11. MARIN MJS, et al. Aspectos das fortalezas e fragilidades no uso das Metodologias Ativas de Aprendizagem. Rev Bras Educ Médica, 2010; 34(1): 13-20.

12. MINISTÉRIO DA SAÚDE. Informações de saúde. Brasília. 2014. Disponível em: http://tabnet.datasus.gov.br. Acesso em 13 fev. 2019.

13. MINISTÉRIO DA SAÚDE. Curso de formação de facilitadores de educação permanente em saúde. 20.ed. Rio de Janeiro: MS/FIOCRUZ; 2005.

14. MITRE MS, et al. Metodologias ativas de ensino-aprendizagem na formação profissional em saúde: debates atuais. Cien\&Saúde Col, 2008; 13(2): 2133-2144.

15. PASCHOAL AS, et al. A educação permanente em enfermagem: subsídios para a prática profissional. Rev Gaúcha Enferm, 2006; 27(3): 336-343.

16. PRADO ML, et al. Arco de Charles Maguerez: refletindo estratégias de metodologia ativa na formação de profissionais de saúde. Esc. Ana Nery, 2012; 16(1): 172-177.

17. SCHAURICH D, et al. Metodologia da problematização no ensino em enfermagem: uma reflexão do vivido no PROFAE. Esc Anna Nery R Enferm, 2007; 1(2): 318-324.

18. Secretaria Estadual de Saúde (SES). Programas do governo do estado - chapéu de palha. Pernambuco; 2014. Disponível em: http://www.cepe.com.br. Acesso em 10 mai. 2019.

19. Secretaria Municipal de Ribeirão Preto (RIBEIRÂO PRETO). Refletindo sobre a educação em saúde. Ribeirão Preto. 2015. Disponível em: http://www.ribeiraopreto.sp.gov.br/ssaude/principal/acervo/i16educa.php. Acesso em: 22 fev. 2019.

20. SILVA IJ, et al. Cuidado, autocuidado e cuidado de si: uma compreensão paradigmática para o cuidado de enfermagem. Esc. de Enferm USP, 2009; 43(3): 697-703.

21. SILVA VG, et al. A prática do enfermeiro na Estratégia Saúde da Família: o caso do município de Vitória/ES. Rev. Eletr. Enf, 2010; 12(3): 441-448.

22. WEIRICH CF, et al. O cuidado de enfermagem à família: um estudo bibliográfico. Rev. Eletr. Enf, 2004; 6(2): 72-80. 